\title{
Doctors Perception of Nursing Care in Lubumbashi City Public Hospitals
}

\section{Ndayi Kabamba Julie ${ }^{1}$, Ilunga Musaya Pierrot ${ }^{2}$, Nyembo Shimba André2, Kabange Umba Irène ${ }^{1}$, Mwinkeu Kasongo Narcisse ${ }^{3}$, Ilunga Kandolo Simon ${ }^{*}$, Omanyondo Ohambe Marie Claire ${ }^{4}$, Malonga Kaj Françoise1,5}

\author{
${ }^{1}$ School of Public Health, University of Lubumbashi, Lubumbashi, Democratic Republic of the Congo \\ ${ }^{2}$ Institute of Medical Techniques of Kamina, Kamina, Democratic Republic of the Congo \\ ${ }^{3}$ Institute of Medical Techniques of Lubumbashi, Lubumbashi, Democratic Republic of the Congo \\ ${ }^{4}$ Institute of Medical Techniques of Kinshasa, Kinshasa, Democratic Republic of the Congo \\ ${ }^{5}$ Faculty of Medicine, University of Lubumbashi, Lubumbashi, Democratic Republic of the Congo \\ Email: *silungak@gmail.com
}

How to cite this paper: Julie, N.K., Pierrot, I.M., André, N.S., Irène, K.U., Narcisse, M.K., Simon, I.K., Claire, O.O.M. and Françoise, M.K. (2019) Doctors Perception of Nursing Care in Lubumbashi City Public Hospitals. Open Access Library Journal, 6: e5579.

https://doi.org/10.4236/oalib.1105579

Received: July 5, 2019

Accepted: August 5, 2019

Published: August 8, 2019

Copyright $\odot 2019$ by author(s) and Open Access Library Inc.

This work is licensed under the Creative Commons Attribution International License (CC BY 4.0).

http://creativecommons.org/licenses/by/4.0/

\begin{abstract}
Introduction: Teamwork is an issue that hospitals must encourage. But the fact is that many hospitals do not promote mutual knowledge of different professions for complementarity in order to meet the needs of patients or the population. Our study pursued a three-fold objective: to explore physicians' perceptions of nursing care, to describe physicians' perceptions of the role of nurses, and to identify some characteristics of physician-nurse collaboration. Method: We conducted a cross-sectional descriptive study with 14 doctors at Lubumbashi General Reference Hospitals (Sendwe, South Gecamines and University teaching hospital). Data collection took three months, from May 1 to July 31,2018 . Of the exhaustive sample of a population of 25 physicians, only 14 physicians freely consented and participated in the study and constituted the final size of our study sample. The data has been processed with Excel 2013 and Epi-info 7 software version 7.2.1.0. Results: At the end of our study, we found that no doctor has been able to define either the term nurse or nursing. In addition, $21.5 \%$ of the doctors thought that the role of the nurse is to execute the decisions of the doctor. Although $78.6 \%$ and $64.3 \%$ respectively strongly agreed on the nurse's consideration as a collaborator and staff needing to clarify a medical prescription; $71.4 \%$ reported that the nurse did not have an independent role, $100 \%$ had no knowledge of the nursing approach, and $100 \%$ found that respect for the role of physicians is one of the elements of their collaboration. In the end, all these results showed the ignorance of the term nurse, nursing care and the nursing approach by the doctors of the public hospitals of the city of Lubumbashi. Conclusion: At the end of our research, we found a negative perception of the nurse and
\end{abstract}


nursing care by the physicians participating in our survey. Awareness within the multidisciplinary team about recognizing the role and limitations of the nurse's skills becomes a necessity. The quality of the doctor and nurse relationship will certainly improve the quality of patient care.

\section{Subject Areas}

Health Policy, Nursing

\section{Keywords}

Perception, Doctor, Nursing

\section{Introduction}

The complexity of current health needs and problems requires the establishment of therapeutic strategies based on interdisciplinary work. Within the care team, collaboration between the various professionals is essential for better care benefits. In the multidisciplinary team, the nurse and the doctor engage, in most cases, in processes of interprofessional exchange. The collaboration between the doctor and the nurse is of paramount importance for the health care provided in the care units [1]. At this point, some physicians feel that collaboration is a way to undermine their authoritarian role within the team [2]. And in Mexico, Hojat M. et al. recommended interprofessional education so that everyone knows the role of the other [3].

Ivory Coast, Brou Ahonzi reported in his study that $100 \%$ of doctors gave neither an exact definition of the nurse, nor the role of the nurse in hospital. In addition, 53\% of doctors were not in favor of setting up the nursing file [4]. In Kinshasa, Zola Kitenge revealed that $15.8 \%$ of doctors said they did not know the autonomous role of the nurse and $7.6 \%$ did not recognize the importance of the nursing profession [5].

The nursing role includes many skills and is carried out according to a care approach to identify the needs of the person, to pose the nursing diagnosis, to formulate the objectives of care, to implement interventions and to evaluate them [6]. Nurses thus have a role of intervention by different acts, but also a reflexive role using the approach of care [7].

As for nurses, it's about having a specific identity to nursing care, to follow a code of nursing ethics. Nurses must also respect their professional boundaries, be aware of their own role and interdependent relationships with doctors. Having a role of one's own also means having some responsibility, because autonomy includes the ability to decide alone. The concept of autonomous role is important because it helps to highlight the skills and responsibilities of nurses, to analyze the complementary medical-nurse by highlighting the importance of nursing care [8].

The prescribed role, including prescription and medical care, is the point of collaboration and interdependence between the physician and the nurse [9]. In 
addition, in the proper role, nurses are autonomous and reflect on the effectiveness and risk of care within the limits of their skills. Because on the medical side, the doctor will deal with the interaction between illness and health [10].

The doctor-nurse collaboration and the impact of this collaboration on the quality of care and the future of patients have mainly been studied in Anglo-Saxon countries.

From these works emerged two archetypal models of physician-nurse collaboration: a hierarchical model (subordination to medical authority and very limited autonomy) and a complementary model (doctors and nurses participate together in decision-making and share responsibilities) [1]. Yet, in true collaboration, power must be mutual and equal [11]. In addition, to optimize the interdisciplinary complementarity between nurse and physician, nursing skills must be used optimally, an evidence-based nursing professional role and a best practice must be developed [2]. Strong interdisciplinary collaboration promotes good quality of care and patient safety.

When the roles of each are clearly defined, collaboration is effective and allows for better patient management, saving time and money, and continuity in management [8]. Some doctors feel that collaboration is a way to undermine their authoritarian role within the team. The importance of collaboration is not sufficiently emphasized in the training of physicians in particular [2].

Lindeke et al. found that nurses do not always feel sufficiently respected in their work by doctors. For this reason, they advise nurses to stop making other professionals responsible for their daily nursing problems, saying that it is because of the doctor, the physiotherapist, the administrators, because this is considered unproductive and unprofessional. In fact, acting as oppressed does not encourage other professionals to respect or trust nurses. Respect is earned by the willingness and courage to share responsibility for health outcomes for patients. By showing their nursing and collaborative skills, trust in their contributions and self-confidence, they will gain respect in the team [12], and Ndayi K. et al, found that in order for nurses in their sample complained: "The nurse is not the assistant of a doctor", "we stop underestimating", "we consider the nurse too", "Do not be hindered by doctors", "collaboration between doctor and nurse is a key word" [13].

Nelson, King, and Brodine suggest that the quality of patient care is a common goal [11].

As for Herrmann et al., they share the same goals to ensure optimal results. And their goal in common is the health of the patient [9].

Literature review articles report similar results and conclude that having a goal and vision in common is very important for collaboration [12] [14].

- Our concerns revolve around the following questions:

- What is the perception of doctors about nursing?

- What is the representation of physicians in the role of the nurse?

- What are the constituent elements of the collaboration between doctors and nurses according to the doctors? 


\section{Methodology}

Our study was carried out in the Democratic Republic of Congo, in the province of Upper Katanga, in the city of Lubumbashi precisely in the following hospitals: Sendwe, South Gecamines and Lubumbashi university teaching hospital.

We conducted a cross-sectional descriptive study over a period of three months, from May 1 to July 31, 2018. The study population consisted of 14 physicians present in our study who met the inclusion criteria (physicians working in these areas). three hospitals, present on the day of the survey, agreeing to answer questions on 25 doctors from these three hospitals). Sampling was exhaustive.

After the ethics committee agreement, we used a questionnaire to collect the data. This questionnaire was tested during the pilot study conducted with doctors at Kamalondo General Reference Hospital, the results of which were not taken into account in this study. The data has been encoded and processed by Excel 2013 and Epi info 7 version7.2.1.0. We limited ourselves to univariate analyzes with frequency tables (Tables 1-4) and figures (Figure 1).

\section{Result}

\subsection{Data Related to Nursing Care Perception}

Table 1. Distribution of respondents according to perceived perception parameters.

\begin{tabular}{|c|c|c|}
\hline 01. Knowledge of the definition of the nurse & $\mathrm{N}=14$ & Percentage \\
\hline a) Yes & 0 & 0 \\
\hline b) No & 14 & 100 \\
\hline 02. Knowledge of the nursing care definition & $\mathrm{N}=14$ & Percentage \\
\hline a) Yes & 0 & 0 \\
\hline b) No & 14 & 100 \\
\hline 03. Consideration of the nurse as a collaborator & $\mathrm{N}=14$ & Percentage \\
\hline a) Totally agree & 11 & 78.6 \\
\hline b) Agree & 2 & 14.3 \\
\hline c) Disagree & 1 & 7.1 \\
\hline 04. Recognition of the nurse's involvement in making service decisions & $\mathrm{N}=14$ & Percentage \\
\hline a) Strongly agree & 3 & 21.5 \\
\hline b) Agree & 10 & 71.4 \\
\hline c) Disagree & 1 & 7.1 \\
\hline 05. Knowledge of the nursing approach & $\mathrm{N}=14$ & Pourcentage \\
\hline a) Yes & 0 & 0 \\
\hline b)No & 14 & 100 \\
\hline 06. Knowledge of the difference in professions between medicine and nursing & $\mathrm{N}=14$ & Percentage \\
\hline a) True & 10 & 71.4 \\
\hline b) False & 4 & 28.6 \\
\hline
\end{tabular}




\subsection{Data on the Representation of Physicians in the Role of the Nurse}

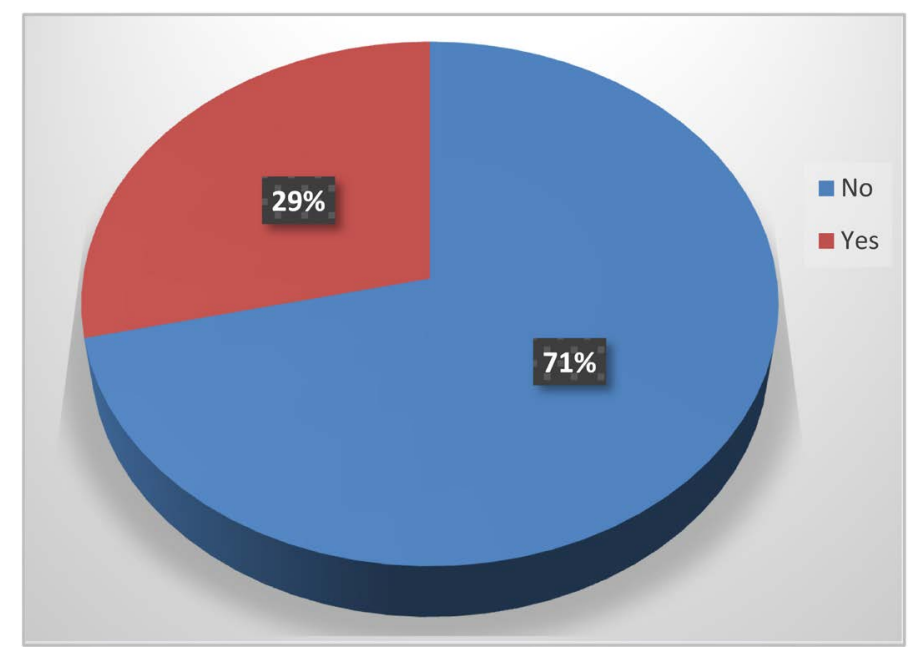

Figure 1. Distribution of physicians by recognition of nurse autonomy.

Table 2. Distribution of doctors according to the holding of the dominant authority for any decision on patients.

\begin{tabular}{ccc}
\hline $\begin{array}{c}\text { The doctor is the dominant authority } \\
\text { over all decisions about patients }\end{array}$ & $\mathrm{N}=14$ & Percentage \\
\hline Totally agree & 4 & 28,6 \\
Agree & 3 & 21,4 \\
Disagree & 7 & 50,0 \\
Total & 14 & 100 \\
\hline
\end{tabular}

\subsection{Data on the Building Blocks of the Doctor-Nurse Collaboration}

Table 3. Distribution of physicians by component of physician-nurse collaboration.

\begin{tabular}{lcc}
\hline \multicolumn{1}{c}{ The building blocks of the collaboration between doctors and nurses } & $\mathrm{N}=14$ & Percentage \\
\hline $\begin{array}{l}\text { Follow-up and application of the instructions given by doctors } \\
\text { (Execution of the prescription) }\end{array}$ & 14 & 100 \\
Simple doctor-nurse relationship & 11 & 78.6 \\
Ignore everything about the doctor-nurse collaboration & 8 & 57.1 \\
\hline
\end{tabular}

Table 4. Distribution of doctors according to proposals for nurses to improve collaboration and play their role in the quality of patient care.

\begin{tabular}{lcc}
\hline Proposals for nurses to play their full role in the quality of patient care & $\mathrm{N}=14$ & Percentage \\
\hline Increase the number of nurses & 7 & 50 \\
Improve the quality of nursing education & 2 & 14.3 \\
Encouraging financially and improving collaboration & 10 & 71.4 \\
Hold monthly meetings & 2 & 14.3 \\
Strengthen evaluation capacity to improve the quality of care & 12 & 85.7 \\
\hline
\end{tabular}




\section{Discussion}

In this study, "Physicians' perceptions on nursing in public hospitals in the city of Lubumbashi”, we targeted: to explore physicians' perceptions on nursing care, to describe physicians' role of nurses and describe the elements of collaboration between doctors and nurses.

\subsection{Physicians' Perception on Nursing}

The results of our study revealed (Table 1) that physicians have a negative perception of nursing and do not know the definition of nurse or nursing. Our results are similar to those of Brou Ahonzi, for whom $100 \%$ of doctors gave neither an exact definition of the nurse nor the role of the nurse in hospital [4]. Our results showed that $7.1 \%$ of physicians did not recognize nurses as their collaborators compared to $78.6 \%$ who strongly agreed. As for the involvement of nurses in decision-making care, only $21.5 \%$ of doctors strongly agreed. This way of looking at nurses does not facilitate collaboration between doctors and nurses, although $78.6 \%$ of physicians strongly agreed that nurses were their collaborators. Some of the physicians questioned (28.6\%), did not even recognize the difference between the nursing and medical professions. These results showed that the perception was negative for these professionals accustomed to nurses often working in pairs within care units. This result is reinforced by the literature that says that some doctors feel that collaboration is a way to undermine their authoritarian role within the team [2]. In reality, collaboration between the doctor and the nurse is of paramount importance, especially for health care provided in care units [1].

Our study revealed that $100 \%$ of our respondents do not know the nursing approach. This result justifies their negative view on the autonomous role of the nurse.

Despite this negative view, some points are positively perceived by physicians: the fact that doctors are aware that nurses are not well paid and that the number of nurses is insufficient ["increasing the number of nurses (50\%)"], To encourage nurses financially (71.4\%), that the doctor is not the dominant authority on all decisions about patients (50\%), acceptance of nurses as their collaborators (78.6\%); physicians' recognition of the nurse's involvement in decision-making (71.4\% of physicians agreed), recognition of physicians of the difference between the medical profession and the nursing profession (71.4\%).

\subsection{Representation of the Nurse' Role}

Our study showed that half of physicians (50\%) agreed that they hold the dominant authority for any decision on patients. Thus, $71.4 \%$ of the doctors said that the nurse does not have an independent role. On the contrary, Zola Kitenge revealed that $84.2 \%$ of the doctors said they knew the independent role of the nurse, $92.4 \%$ declared to recognize the importance of the nursing profession [5]. In our study, the surveyed physicians therefore represented nursing as a disci- 
pline dependent on medicine and that the nurse is always a medical assistant as supported by an author who says the nurse works according to the hierarchical model, where, it is subordinate to the medical authority and has very limited autonomy in the field of care [1]. When there is a hierarchical difference, professionals at the top of the hierarchy (here doctors) may seem unapproachable, and professionals at the bottom of the hierarchy (here nurses) may feel intimidated and uncomfortable talking about problems patients. This may result in a decrease in the interactions needed to ensure the administration of the appropriate treatments, and thus increase the risks for the patient [1]. In true collaboration, power must be mutual and equal [11].

We therefore understand the source of the nurses' complaints about the blocking of the implementation of the nursing approach. In another study on the impediments to the implementation of the nursing approach, Ndayi et al, noted the following statements by nurses: "The nurse is not the assistant of a doctor", "Do not be hindered by doctors", "it takes collaboration between doctor and nurse" [13].

Our respondent argumentations would be justified by the fact that the doctors did not learn to work in collaboration with the nurse to know the limits of two professions. They believed that nurses were executors of their decisions, which is totally wrong.

Thus the importance of collaboration is not sufficiently emphasized in the training of physicians in particular. Doctors often have expectations that suggest that nurses are an extension of them, which no longer corresponds to current nursing skills and roles [2].

\subsection{Elements of the Collaboration}

Regarding the collaboration between doctor and nurse, our study has shown that it can be summarized by the follow-up and the application of instructions given by doctors as $100 \%$ of doctors say.

\subsection{Limitations}

Our first limitation is the small number of selected public hospitals. Yet private and conventional hospitals could give us perhaps another story in order to generalize our results in Lubumbashi. A second limitation is the choice of doctors and no other health professionals as a team of care within a care unit.

\section{Conclusions}

At the end of our study, we observed that physicians have a negative perception of nursing care. They consider a nurse as a professional with no independent role. The respect of the instructions and orders of the doctors constituted the capital element of the doctor-nurse collaboration.

Awareness within the multidisciplinary team about recognizing the role and limitations of the nurse's skills becomes a necessity. The quality of the doctor 
and nurse relationship will certainly improve the quality of patient care.

\section{Recommendations}

\section{To the politico-administrative and health authorities:}

- Design a policy based on the collaboration between doctors and nurses across the national territory,

- Design an approach aiming at a mutual consensus between doctors and nurses in the exercise of their professions,

- Design strategies for collaboration and merit of medical actors in hospital settings,

- Ideally, train doctors and nurses in the same schools.

To the Doctors:

- Promote training sessions in order to build the capacity of each other,

- Promote dialogue and communication with nurses in the respect and consideration of the role of each other,

- Recognize the autonomous role of the nurse at the hospital.

\section{Conflicts of Interest}

The authors declare no conflicts of interest regarding the publication of this paper.

\section{References}

[1] May, S.L. and Perrier, A. (1995) Collaboration infirmières-médecins: Un déterminant de la qualité des soins ? Revue Médicale Suisse, 1, 308.

[2] Day, C., Hendricks, D., Wiesman, T., et al. (2008) Nurse-Physician Work Relations and Role Expectation. JONA: The Journal of Nursing Administration, 37, 68-70. https://doi.org/10.1097/00005110-200702000-00007

[3] Hojat, M., Gonnella, J.S., Nasca, T.J., et al. (2003) Comparisons of American, Israeli, Italian and Mexican Physicians and Nurses on the Total and Factor Scores of the Jefferson Scale of Attitudes toward Physician-Nurse Collaborative Relationships. International Journal of Nursing Studies, 40, 427-435.

https://doi.org/10.1016/s0020-7489(02)00108-6

[4] Ahonzi, B. (2007) Mise en place du dossier infirmier dans les services de santé en Côte-d'Ivoire. Institut National de Formation des Agents de Santé d'Abidjan. http://www.memoireonline,.com/04/10/3280/m-Mise-en-place-du-dossier-infirmie r-dans-les-service

[5] Kitenge, Z. (2013) perception et contribution des professionnels soignants dans la professionnalisation médicale, ouvrage, 143.

[6] Association Suisse des Infirmiers (ASI) (2006) l'Ethique dans la pratique des soins infirmiers.

[7] Kvande, M., Lykkeslet, E. and Storli, S.L. (2017) ICU Nurses and Physicians Dialogue Regarding Patients Clinical Status and Care Options-A Focus Group Study. International Journal of Qualitative Studies on Health and Well-Being, 12, Article ID: 1267346. https://doi.org/10.1080/17482631.2016.1267346

[8] San Martín-Rodríguez, L., Beaulieu, M.D., D’Amour, D. and Ferrada-Videla, M. 
(2005) The Determinants of Successful Collaboration: A Review of Theoretical and Empirical Studies. Journal of Interprofessional Care, 19, 132-147. https://doi.org/10.1080/13561820500082677

[9] Herrmann, L.L. and Zabramski, J.M. (2005) Tandem Practive Model: A Model for Physician-Nurse Practitioner Collaboration in a Specialty Practice, Neurosurgery. Journal of the American Academy of Nurse Practitioners, 17, 213-218.

[10] Neurès, K.L. and Siebert, C. (2009) Raisonnement démarche clinique et projet des soins infirmiers. Elsevier Masson, Paris.

[11] Nelson, G.A., King, M.L. and Brodine, S. (2008) Nurse-Physician Collaboration on Medical-Surgical Units. MEDSURG Nursing, 17, 35-40.

[12] Lindeke, L.L. and Sieckert, A.M. (2005) Nurse-Physician Workplace Collaboration. OJIN: The Online Journal of Issues in Nursing, 10, Manuscript 4.

[13] Julie, N., Simon, I., Charles, M., Irène, K., Mahuridi, A., Narcisse, M., Henry, M., Claire, O. and Françoise, M. (2017) Factors Associated with the Implementation of the Nursing Process in the Public Hospitals of Lubumbashi in the Democratic Republic of Congo: A Cross-Sectional Descriptive Study. Open Access Library Journal, 4, 1-9.

[14] Choi, B.C.K. and Pak, A.W.P. (2007) Multidisciplinarity, Interdisciplinarity, and Transdisciplinarity in Health Research, Services, Education, and Policy: 2. Promotors, Barriers, and Strategies for Enhancement. Clinical and Investigative Medicine, 30, E224-E232. https://doi.org/10.25011/cim.v30i6.2950 